Bayero Journal of Pure and Applied Sciences, 4(1): 75 - 78

Received: November, 2010

Accepted: April, 2011

ISSN 2006 - 6996

\title{
THE ANTI-BACTERIAL POTENTIALS OF PHAGE-THERAPY: A REVIEW
}

\author{
*A.H. Arzai. ${ }^{1}$ and S.S. Samira ${ }^{1}$ \\ ${ }^{1}$ Department of Biological Sciences, Bayero University, P.M.B. 3011, Kano- Nigeria. \\ *Correspondence author:auwalarzai@yahoo.com
}

\begin{abstract}
Bacterial infections are among the major indices of health hazard threatening public health and welfare. They are the leading cause of starvation and death the world over. Several methodologies were applied to combat the menace among which are the use of chemotherapy, immunotherapy, probiotics, and other preventive measures. Ironically, despite all the advancements in technological know-how and high medical-care, these methodologies have adverse side effects and drug resistant strains of bacteria are increasing at an alarming rate due to over-prescription and misuse of drugs. The consequent effect of which poses a threat to modern medicine that if care is not taken, untreatable bacterial infections might soon reach a point beyond control; which would subsequent/y lead to the re-emergence of diseases with fatal consequences. One such measure of combating this menace is the use of phage-therapy, which is the nature's own method of controlling bacteria. It involves the use of bacteriophages (small viruses that predate bacteria) to cure bacterial infections. It is quicker, safer and specific in action with no side effects. This study aimed at enhancing the understanding of the potentials of phage-therapy in the prevention and treatment of bacterial infections and other microbial pathogens. This was achieved through comparison with the most common and contemporary methods available in the world today.
\end{abstract}

Keywords; Antibiotics, Bacteriophages, Chemotherapy, Immunotherapy, Phage-therapy.

\section{INTRODUCTION}

Bacteria being the most cosmopolitan organism in the biosphere, with approximately five nonillions $\left(5.0 \times 10^{30}\right)$ representative members (Whitman et al., 1998), are the major cause of diseases known to man. Despite the fact that some bacteria are friends to man and his animals, others are foes leading to wide spread of epidemics and death in both flora and fauna (Anonymous, 2009). They may be spread in air, carried in arthropod (insect and spider) vectors, through direct contact or passed in water or food inducing a wide range of clinical symptoms such as: Legionellosis (a kind of pneumonia caused by Legionella pneumophila), pertussis (caused by Bordetella pertussis), diphtheria (caused by Corynebacterium diphtheriae), tuberculosis (caused by Mycobacterium tuberculosis), meningitis (caused by Mycobacterium meningitidis), Lyme's disease (caused by Borrelia burgdorferi), bubonic plague (caused by Yersinia pestis), gonorrhoea (caused by Neisseria gonorrhoeae), anthrax (caused by Bacillus anthracis), salmonellosis (caused by Salmonella enteritidis), cholera (caused by Vibrio cholerae) (Lewis et al., 2002), to over-whelming sepsis, systemic inflammatory response producing shock, massive vasodilatation and death (Periti, 2001). Their pathenogenicity depend upon their transmissibility, adherence to host cells, invasion of host cells and tissues, toxigenicity and ability to invade host's immune system (Govan and Deretic, 1996). The aim of this study is to highlight the potentials of phagetherapy over the current therapeutic methods used in the treatment of bacterial diseases.

Several methods for combating bacterial infections have been devised and put into practice amongst which are; Chemotherapeutic method; Immunotherapeutic method; and Probiotics administration method.

Chemotherapeutic Method of Controlling Bacterial Infections

Chemotherapy denotes the use of certain chemical agents in the treatment of diseases (Taylor et al., 2005; Yusha'u et al., 2010). It is used in the treatment of an illness or other medical conditions using drugs/chemicals. The term most commonly refers to the treatment of cancer using specific drugs such as colchicines designed to destroy cancer cells, thereby slowing or reversing the growth rate of tumors. The drugs used in chemotherapy attack a specific tumor; by preventing tubulins from assembling into microtubules, or by preventing microtubules from breaking down into free tubulin dimers stopping cell division (Lewis et al., 2002) or DNA synthesis and functions; while some such as monoclonal antibodies the new tyrosine-kinase inhibitors do not directly interfere with DNA, and which might otherwise form new tumors (Anonymous, 2009).

The drugs specifically kill microbial and cancerous cells. When used against bacteria, the antibacterial chemotherapy destroys bacterial cells. Some of these drugs such as quinolones enter host cells via porins to destroy intracellular pathogens such as L. pneumophila and Mycoplasma pneumoniae as well as many other gram-negative bacteria by inhibiting the bacterial DNA gyrase and topoisomerase IV of many gram-positives (Norris and Mandell, 1998). 
The chemotherapeutic agents act by killing rapidly dividing cells as such can affect normal proliferating cells of the liver, bone marrow, digestive tract and hair follicles (Hirsch, 2006). The rapid evolution of quinonone resistance, even during the course of treatment by numerous bacterial strains such as Staphylococcus aureus, Enterococci spp., and Streptococcus pyogenes is another side effect of using chemotherapy (Norris and Mandell, 1998). Furthermore, some chemotherapeutic agents such as Ciprofloxacin and Levofloxacin, used against life threatening bacteria, increased the risk of cardiotoxicity, arrhythmiasis, anti-coagulant effects and non-absorbable complexes formation as well as the risk of toxicity (Cabeen and Jacobs-Wagner, 2005). Moreover, frequent use of chemotherapeutic agents leads to rapid evolution of drug resistant bacterial strains such as Staphylococcus aureus, Enterococci spp. and Streptococcus pyogenes (Norris et al., 2007), besides several side effects such as nausea, diarrhea, constipation and anaemia.

Antibiotics are substances mostly produced by bacteria and few fungi that kill or inhibit microbial growth of infectious organisms (Donnenberg, 2000). They are chemicals, which in low concentrations, can selectively kill or inhibit the growth of most pathogenic microorganisms. They are generally used to control diseases caused by pathogenic bacteria (Yusha'u et al., 2010). The action of individual antibiotics varies with the location of the infection, the ability of the antibiotic to reach the infection site and the ability of the microbe to inactivate or excrete the antibiotic. The antibacteriocidal activity of the antibiotics is mostly growthphase-dependent (Nicholson et al., 2000). They can have a narrow spectrum i.e. targeted particular types of bacteria by having a specific target on either gramnegative or gram-positive bacteria, or can have a wide spectrum i.e. affect a wide range of bacterial strains. The Tigecyclines for instance have a wide spectrum of anti-bacteriocidal action, while Daptomycin and Linezolid have narrow spectrum as they tend to act vigorously on Gram-positive bacterial strains. Some, such as penicillin and cephalosporin, targeted bacterial cellwalls inhibiting the synthesis of peptide link between the cellwall molecules, leading to bursting or lysing of the cellwall. Some affect the cell membranes such as polymyxins or interfere with essential bacterial enzymes such as quinolones, aminoglycosides, macrolides and tetracyclines (Pelczar et al., 1999). However, some antibiotics such as streptomycin, chloramphenicol and tetracycline bind to 70s bacterial ribosomes inhibiting RNA and protein synthesis in the bacterial cell (Walsh and Amyes, 2004). Some antibiotics such as Chloramphenicol, Erythromycin, Sulphonamides and Tetracyclines are biostatics i.e. inhibit the growth and multiplication of susceptible organisms. But growth and multiplication of the organisms resume if the agent is removed. However, some antibiotics such as streptomycin, cephalosporins, penicillins and polymyxins are biocidals i.e. kill the microorganisms (Taylor et al., 2005).

Prolong use and misuse of antibiotics make some of the bacterial strains to be tolerant to their actions, thereby becoming resistant to such drugs. Slight change in the target of the antibiotic makes it ineffective such as resistance to streptomycin due to change in ribosomal structure to which the antibiotic binds. A change in only one amino acid in one of the ribosomal proteins as a result of mutation can be sufficient in inducing antibiotic resistance (Poehlsgaard and Douthwaite, 2005). The over-use and misuse of antibiotics give room for the breeding of super bacteria resistant to entire antibiotics (Nicholson et al., 2000) through the evolution of mutants with slightly different molecules in their cellwalls that the antibiotic cannot alter (Lewis et al., 2002). The emergence of antibioticresistant bacteria is therefore closely related to the extent to which antibiotics are used in humans and items of human diet. Resistance may also occur through exclusion of the antibiotic or destruction by enzymes inside the cells being targeted. For instance, a group of enzymes known as penicillinases hydrolyses and destroys penicillins and cephalosporins; meaning that the bacterium has developed resistance to those antibiotics (Taylor et al., 2005). Beside these, antibiotics confer side effects that can be fatal depending on the type of antibiotic used and the microbe targeted. The adverse effects ranges from fever, nausea, allergy, diarrhea (Anonymous, 2010) and the subsequent effect of disrupting the balance of the normal microbial flora leading to over-growth of fungal species such as Candida albicans in vulvovirginal area (Piroha and Garland, 2006).

\section{Immunotherapeutic Method of Controlling Bacterial Infections}

The immune system is remarkably effective at keeping potentially infectious bacteria, viruses and tumor cells from invading the body systems. This efficacy of the immune system can be amplified (Lewis et al., 2002). Immunotherapy is the use of Biological Response Modifiers through an array of treatment strategies based upon the concept of modulating the immune system to achieve a prophylactic and/or therapeutical goal. These modifiers are agents that modify the hosts' response to pathogens with resultant beneficial prophylactic or therapeutic effects. Biological Response Modifier-agents include vaccines, interferons and interleukins (Rosenberg et al., 1990). Immunity to infectious organisms can be achieved by active or passive immunization. The goal of passive immunization is a transient protection or alleviation of an existing condition, whereas the goal of active immunization is the elicitation of protective immunity and immunologic memory. Active and passive immunization can be achieved by natural or artificial means (KAPLAN, 2008). When a single B cell for instance recognizes a single foreign antigen, it manufactures a single or monoclonal type of antibody. A large amount of a single antibody type would make a powerful drug because of its great specificity. It could be used to target a particular pathogen or cancer. The monoclonal antibodies (MAb) are therefore pure preparations of a single antibody type that recognize a single antigen. They are useful in diagnosing and treating diseases because of their specificity (Lewis et al., 2002). 
The limitations of immunotherapy lie on the fact that they are useful only for people with allergic rhinitis, asthma or more recently people with advanced skin cancerous tumors (Rosenberg et al., 2008).

Other risk factors associated with immunotherapy include the generation of IgG or IgM anti-isotype antibodies through the introduction of antibodies from other species leading to Type III hypersensitivity reactions or if $\mathrm{IgE}$ antibodies are generated cause systemic anaphylaxis. It can also elicit responses against minor immunoglobulin polymorphisms or allotypes (KAPLAN, 2008).

\section{Probiotics Method of Controlling Bacterial Infections}

Probiotics administration involves the employment of live culture which may establish itself as symbionts competing, inhibiting or simply interfering with colonization of pathogens. They may produce antibiotics or bacteriocin, especially providing the drug in-vivo and in-situ, thereby avoiding side effects of systemic administration. Probiotics are live microorganisms such as lactic acid bacteria $(\angle A B)$ which when administered in adequate amount confer a health benefit on the host (Anonymous, 2009). Although probiotics are claimed to strengthen the immune system, combating allergies, excessive alcoholic effects, stress, exposure to toxic substances and other related diseases, they are potentially harmful in critically ill patients (Nichols, 2007). They were found to increase the death rate of patients with acute Pancreatitis (Anukam et al., 2008). Recent research on the molecular biology and genomics of LAB has focused on the interaction of the immune system, anti-cancer potential and potential as a bio therapeutic agent in cases of antibiotic associated diarrhea, traveler's diarrhea, pediatric diarrhea, inflammatory bowel disease and irritable bowel syndrome (Anonymous, 2010).

\section{Phage-therapy Method of Controlling Bacterial Infections}

Bacteriophages or 'phages' are the most profuse organisms on earth. It was estimated that $10^{25}$ phages commence new infection cycle every second of the day (Pedulla et al., 2003). They exhibit extraordinary diversity found in any environment colonized by bacteria to the extent that there is hardly a single species of bacteria where sufficient investigation has not found a phage. The phage nucleic acids exist either as double- or single- stranded DNA, or as a single-or double- stranded RNA (Schlegel, 2002). They are any of various viruses that are parasites of bacteria. Bacteriophages that lyse a variety of indigenous bacteria including Pseudomonas spp., Agrobacterium spp., Photobacterium spp., and various non-marine contaminants, particularly members of Enterobacteriaceae (Schlegel, 2002) were isolated. Due to their remarkable antibacterial activity, phages have been used to treat human and economically valuable animal infections since before the early 40s. During World War II, phage-therapy received momentum among the Soviet forces that used it to treat many soldiers infected by various bacterial diseases such as dysentery and gangrene. The success rate was as good as, if not better than, that of any antibiotic (Sooltill, 2002). Since the 1940s, research with bacteriophages, has resulted in establishing nucleic acids as the genetic material of life and has been central in the new field of molecular biology (Anonymous, 2009). Political reasons associated with cold war (Summers, 2001) and the advent of antibiotics caused a decline of phage-therapy. The presence of phages is recognized by the appearance of plaques or lytic holes in continuous bacterial lawn which in bacterial suspension can easily lead to a complete lysis in a short period of time (Schlegel, 2002).

Phage-therapy is currently a conventional therapeutic method of combating infections caused by bacterial populations (Parfitt, 2005). It was discovered further that a phage could integrate its genes into that of its bacterial host and be transmitted from generation to generation as part of the host's own chromosome (Anonymous, 2009). In the case of some bacterial species such as Haemophilus influenzae and Bacillus subtilis, native DNA isolated from bacteriophages can infect them through a process of genetic transformation called 'transfection' (Schlegel, 2002). Phages tend to be more successful than antibiotics and other therapeutic methods because of their relative ability to eradicate bacterial infections and chronic polymicrobial bio-films along with other strategies. They were recently been used in systemic and intracellular infections (Piris, 2000). Results from 500 trials in 1994 had demonstrated that, phage-therapy could improve the success of skin grafts by reducing the underlying Pseudomonas aeruginosa infection. Its significance in preliminary in-vitro experiments for cells in tissue culture against tumor agents had also been established (Bar et al., 2008). Even though phages are non-motile, a suspension of free phage particles when mixed with a suitable bacterial suspension leads to the attachment of the phage particle to a bacterial surface through adsorption, followed by injection of the phage DNA. Eventually, after a period of synthesis and maturation of phages, lysis of the host cells liberates newly formed phage particles into the suspending medium (Schlegel, 2002).

Bacterial infections treated with phage-therapy include, among others: laryngitis, dermatitis, dysentery, conjunctivitis, periodontitis, sinusitis, urinary tract infections, burns, boils and polymicrobial films on chronic wounds (Summers, 2001). It had also been successfully used against Campylobacter in raw foods, Listeria in fresh foods (McGrath and Van Sindren, 2007), Lactococcus and Vibrios in fish aquaculture and against wound infections caused by facultative microbes such as Staphylococcus and Streptococcus strains. Phage therapy was used by the United States Food and Drug Administration (FDA) to control Listeria monocytogenes bacteria in cheese, making it safe for consumption. The study of phages has important implications in medicine and genetics, specifically in the understanding of virus infections, genetic defects, human development and mal-development, the causes of cancer, and resistance of bacteria to antibiotics (Anonymous, 2009). 
Although bacteria are able to develop resistance to phages, the resistance might easily be over-come. Phages are more specific in action, targeting only single or few strains of bacteria (Schlegel, 2002). More so, traditionally, antibiotics usually have a wide range of side effects, killing both harmful and useful bacteria such as those facilitating food digestions, but phages attack a specific bacterial strain. Furthermore, phage therapy is free from severe adverse effects as compared to other therapeutic methods and is faster in action once the exact bacteria are identified and phage administered. It is therefore a promising approach in combating antibiotic and other therapeutic resistant

\section{REFERENCES}

Anonymous (2009): 1940: Medicine. Microsoft student 2009 [DVD],Archived article. In: Microsoft Encarta Encyclopedia retrieved July 13, 2009.

Anonymous (2010): Wikipedia. In: http://www.wikipedia.com Retrieved July 13, 2009.

Anukam, K.C., Osazuwa E.O., Osadolor, H.B., Bruce, A.W., Reid, G.(2008): Yoghurt containing probiotic Lactobacillus rhamnosus GR-1 and $L$. reuteri RC14 helps resolve diarrhea and increases CD4 count in HIV/AIDS patients. Journal of Clinical Gastro-enteritis 42(3):239-43.

Bar, H., Yacoby, I., and Benhar, H. (2008):Killing cancer cells by targeted drug-caying phage nanomedicines. BMC Biotechnology 8(37):

Cabeen, M., and Jacobs-Wagner, C. (2005): Bacterial cell shape. Nat Rev Microbio/3(8):601-10.

Donnenberg, M.S. (2000); Pathogenic Strategies of enteric bacteria. Journal of Nature 406: 768-74.

Govan J. R., and Deretic, V. (1996): Microbial Pathogenesis in cystic fibrosis. Microbiol. 60:539-74

Hirsch, J. (2006): An Anniversary for cancer chemotherapy. Journal of JAMA 296 (12):151820.

KAPLAN (2008): Immunology at a glance for clinical and laboratory students. In: http//:eduthrapy@ymail.com Pp 403-404. Retrieved March, 2010.

Lewis, R., Gaffin, D., Hoefnagels D. and Parker, B.(2002): Life. Mc Graw Hill, New York, pp1-972.

McGrath, S., and Van Sindren D. (2007): Bacteriophage: Genetics and Molecular Biology $1^{\text {st }}$ Ed. Caister Academic Press Ireland.

Nichols, A.W. (2007): Probiotic and athletic performance: A systematic review. Journal of Current Sports Medicine Reports 6(4): 269-273.

Nicholson, W., Munakata, N., Horneck, G., Melosh, H. and Setlow, P.(2000): Resistance of Bacillus endospores to extreme terrestrial and extraterrestrial environments. Microbiol. Mol Biol Rev 64(3): 548-72.

Norris S. and Mandell G. L (1998); The quinolones history and over-view. In: Andriole V.T. (eds) Academic press, Sandiego pp1-22.

Norris V., den Blaauwen T. and Cabin-Flaman A. (2007): Functional taxonomy of bacterial hyperstructures. Microbiol. Mol. Biol. Rev. 71(1):230-53.

Parfitt, T. (2005): Georgia, an unlikely stronghold for bacteriophage therapy. Journal of Lanct. 365(9478):2166-7. pathogens. The cost of isolation and preparation of phage solutions are far less than those for antibiotics. Recent Polish trial on immune response to phages has demonstrated the effects of phages as therapeutically significant. Beside these, bacteriophages can be easily isolated by suspending a host bacterium in a nutrient medium and inoculating with material from a location where the bacterial strain occurs naturally (Schlegel, 2002). Thus, phage-therapy could serve as a complimentary promising method of treating bacterial infections, more particularly those caused by drug resistant bacterial strains.

Pedulla, M.L., Michael, E.F., Ford, T.K., Roger, W.H. and Graham F.H (2003): Bacteriophages. Journal of Bacteriophage 185 (4):1475-1477

Periti, P. (2001): Current treatment of sepsis and endotoxaemia. J. Expert Opinion Pharmacother 1:1203-17.

Pelczar, M.J., Chan, E.C.S. and Krieg V. R. (1999): Microbiology. Concepts and applications. $6^{\text {th }}$ Edition. pp478-479.

Piris, A. (2000): Phage therapy, advantages over antibiotics. Journal of Lanc. 356(9239):14-18.

Piroha, M.V. and Garland, S.M. (2006): Clinical microbiology. McGrath pub 2313-2317pp.

Poehlsgaard, J. and Douthwaite, S. (2005): The bacterial ribosome as a target for antibiotics. Nat Rev. Microbio/ 3(11):870-81.

Rosenberg, S.A., Aebersold, P., Cornetta, K., Kasid, A., Morgan, R.A., Moen, R., Karson, E.M., Lotze, M.T., Yang, J.C. and Toplain, S.L. (1990): Gene transfer into humans- immunotherapy of patients with advance melanoma using tumour-infiltrating lymphocytes modified by retroviral gene transduction. Journal of National Medicine $\mathbf{3 2 9}$ (9)570-578.

Rosenberg, S.A., Restipo, N.P., Yang, J.C., Morgan, R.A and Dudley, M.E. (2008): Adoptive cell transfer; A clinical path to effective immunotherapy. Journal of National Review in Cancer 8(4):299308.

Schlegel, H. G. (2002): General microbiology. Seventh Edition, Cambridge University Press, UK pp 1655.

Sooltill, J. S. (2002): Bacteriophage prevents destruction of skin graft by Stalin's forgotten cure. Science Magazine, Vol. 298, October, 2002.

Summers, W.C. (2001): Bacteriophage therapy. Journal of Annual Review Microbiol. 55(3): 437-51.

Taylor, D.J., N.P.O. Green and G.W. Stout (2005): Biological Sciences, Cambridge University press, London. pp 1792.

Walsh, F. and Amyes, S. (2004): Microbiology and drug resistance mechanisms of fully resistant pathogens. Curr. Opin. Microbio/7(5):439-44.

Whitman, W, Coleman, D. and Wiebe, W (1998): Prokaryotes: the unseen Majority. Proc. Natl. Acad SciUSA 95 (12): 6578-83.

Yusha'u M., Isa, A. and Kawo, A.H. (2010): Basic Microbiology, Benchmark publishers Ltd Kano, pp16. 